\title{
Medidas a seguir para el levantamiento del secreto de las comunicaciones y telecomunicaciones (arts 230 y 231 del NCPP)
}

Prof. Gilberto BLANCAS CAMPOS

\section{Introducción}

La noticia de hace unas semanas, referida a la interceptación telefónica sufrida por el congresista Luis Galarreta revela otra realidad de que el derecho a la privacidad de las comunicaciones en el Perú es meramente nominal pues no es respetado ni por el propio Estado, y que además de la afectación de los derechos del citado congresista, constatamos lo indefenso que se encuentra el ciudadano común frente al poder de los fiscales y jueces. Esto nos lleva a preguntarnos sobre cuántas personas que jamás han cometido un delito están siendo escuchadas debido a que, sin mayor diligencia, se les ha levantado el secreto a las comunicaciones por el simple hecho de que ocasionalmente sus números telefónicos aparecieron en el reporte de llamadas de quien está siendo investigado por un ilícito penal.

Fue el fiscal William Montes quien solicitó al juez Abel Pulido, del Tercer Juzgado Supraprovincial de Lima, el levantamiento de las comunicaciones de 21 números telefónicos y seis correos electrónicos, en el ejercicio de sus potestades jurisdiccionales.

Se indica que el fiscal fundamentó su solicitud en que las cuentas de correo y el teléfono celular asignados a Rudy Palma estarían siendo utilizados por éste y otros supuestos integrantes de una organización criminal, para coordinar actividades relacionadas con los delitos investigados.

El fiscal sustentó su pedido en la Ley $\mathrm{N}^{\circ} 27697$, que otorga facultades al fiscal para la intervención y el control de las comunicaciones y los documentos privados en caso excepcional, y en la Ley $\mathrm{N}^{\circ} 27379$, que norma el procedimiento para 
adoptar medidas excepcionales de limitación de derechos en investigaciones preliminares.

El juez Pulido, acogiendo el requerimiento fiscal, autorizó las medidas por un plazo de 60 días, desde el 28 de abril último del año en curso 2012.

Asimismo, se dispuso que cuatro empresas de comunicaciones remitan la información vinculada con los números telefónicos objeto de la intervención, la identidad de sus propietarios y usuarios, el registro histórico de llamadas, así como que la empresa Google Inc. informe sobre las seis cuentas de correo. Es cierto que los jueces y fiscales tienen plena autonomía en el ejercicio de su función de perseguir el delito, sin embargo, no debe olvidarse que esta autonomía más que una atribución de los magistrados es una garantía de la administración de justicia y un derecho fundamental de los ciudadanos; por lo que en ningún caso los funcionarios de la administración de justicia tienen patente de corso o están exentos de límites para ejercer sus atribuciones, más aún cuando las medidas que se adoptan están orientadas a afectar un derecho fundamental como es el secreto a las comunicaciones.

De ahí que la Constitución reconozca todo un conjunto de garantías que constituyen límites al poder de los jueces y fiscales, que al propio tiempo son derechos esenciales de las personas. En el caso particular del levantamiento del secreto de las comunicaciones, además de existir un procedimiento legalmente establecido, el pedido del fiscal debe expresar una especial fundamentación y razones objetivas que vinculen al investigado con la comisión del delito; y dicha fundamentación debe ser aún más exigente cuando el levantamiento se va a ordenar contra una persona no vinculada a la investigación. El solo hecho de que un ciudadano haya llamado a quien se encuentra investigado no habilita al fiscal para solicitar al juez que se ordene una interceptación telefónica.

Si bien el fiscal debe guardar especial cuidado en estos casos, el juez no puede actuar como simple tramitador del pedido de interceptación telefónica sino que debe cumplir con verificar la legalidad, la razonabilidad y la proporcionalidad de la medida solicitada, todo esto por tratarse de una medida de última ratio que, como ya se ha dicho, afectará un derecho fundamental.

Lo paradójico de todo es que una mal entendida autonomía de estos funcionarios de justicia está conduciendo, en este y otro tipo de medidas, a afectar precisamente a quienes dicha garantía está destinada a proteger: los ciudadanos. Si esto ha sucedido con un congresista que tiene inmunidad parlamentaria, ¿qué podemos esperar que pase con un hombre común? 
El verdadero Estado de Derecho es el que protege no a quienes tienen poder sino a quienes carecen de él, y el poder que se otorga a los jueces y fiscales es para que protejan a los ciudadanos, no para que atropellen sus derechos.

Pues bien, frente a ello, trataremos de exponer en forma concisa las principales disposiciones por las que se rige la intervención de comunicaciones y telecomunicaciones en el Nuevo Código Procesal Penal en adelante NCPP, aprobado mediante el DLeg $\mathrm{N}^{\circ} 957$.

El fin fundamental del Proceso Penal es la actuación del Ius Puniendi Estatal, que obedece o proviene de la atribución exclusiva de la imposición de una pena al Estado; el Estado tiene el derecho, pero, también el deber, de castigar las conductas delictivas de las que tenga conocimiento; ese derecho-deber sólo pueden ejercitarlo los jueces y tribunales a través del Proceso Penal.

Hay que tener en cuenta, en todo caso que el ejercicio de ese derecho-deber, por definición, ha de quedar sujeto al principio de legalidad o necesidad; y además, su carácter público lo convierte en indisponible para su titular: el Estado.

Lo antes mencionado parte del inciso tercero del artículo 139 de la Constitución, nos referimos al Debido Proceso Formal, que constituye un derecho fundamental cuyo contenido esencial es la exigencia que todo proceso, tenga que desarrollarse con irrestricto respeto de un conjunto de derechos y principios de naturaleza procedimental para que sea considerado como justo o conforme a Derecho (Due process of law).

La investigación del delito en un Estado de Derecho, no tiene límites siempre y en cuando dicha investigación se lleve a cabo con estricto respeto de los derechos fundamentales de las personas investigadas, derechos fundamentales que a su vez no son absolutos, sino admiten limitaciones como las que legítimamente puede adoptar el juez en aras de un fin superior como es el esclarecimiento de un hecho delictivo que pone en riesgo la convivencia en sociedad.

Es así que en el NCPP, las limitaciones de los derechos fundamentales dentro del marco de la investigación del delito otorgan al Juez un protagonismo importante y exige a su vez una responsabilidad en su adopción o negación, dándose así cumplimiento a su papel constitucional de garante de dichos derechos.

Uno de las medidas que el NCPP prevé para limitar el derecho fundamental del secreto a las comunicaciones y telecomunicaciones dentro de la investigación criminal es la intervención de las comunicaciones, medida que ha resultado eficaz en la lucha contra la criminalidad organizada y otras formas de delincuencia grave. 
Sin embargo su adopción requiere extremar precauciones para poder equilibrar entre la actividad de investigación y respeto de los derechos fundamentales de la persona.

\section{Principios para la limitación de los derechos fundamentales}

Ladoctrinayjurisprudencia tantonacional comode los Tribunales internacionales han venido señalando los principios de carácter general que deben cumplir las intromisiones de parte del órgano estatal en los derechos fundamentales de las personas para ser consideraras constitucionalmente válidas; algunos de estos principios se encuentra reconocidos a su vez en nuestra legislación en el Art. VI del Título Preliminar del NCPP.

1. Legalidad: Las medidas destinadas a limitar derechos fundamentales deben estar avaladas por una norma constitucional o legal.

2. Motivación: La motivación de las resoluciones judiciales y más aún las que restringen derechos fundamentales ha pasado de una simple exigencia legal desoída por los jueces a ser una exigencia constitucional, así lo ha establecido el Tribunal Constitucional en abundante jurisprudencia como la expedida en el proceso $\mathrm{N}^{\circ}$ 00728-2008-PHC/TC, donde ha señalado: "El derecho a la debida motivación de las resoluciones judiciales es una garantía del justiciable frente a la arbitrariedad judicial y garantiza que las resoluciones no se encuentren justificadas en el mero capricho de los magistrados, sino en datos objetivos que proporciona el ordenamiento jurídico o los que se derivan del caso". Debemos también agregar que esta decisión debe basarse en criterios de razonabilidad. La motivación exigida no tiene más fin que la persona a la cual se ha limitado sus derecho fundamental tenga conocimiento de las razones por las que sus derechos se vieron limitados y además en virtud de que otros intereses se llevó a cabo dicha intervención.

3. Necesidad e idoneidad: De acuerdo con este principio para que una injerencia en los derechos fundamentales sea necesaria, no debe existir ningún otro medio alternativo que revista, por lo menos, la misma aptitud para alcanzar el objetivo propuesto y que sea más benigno con el derecho afectado. Se trata de una comparación de la medida adoptada con los medios alternativos disponibles, y en la cual se analiza, por un lado, la idoneidad equivalente o mayor del medio alternativo; y, por otro, su menor grado de intervención en el derecho fundamental. De acuerdo con el principio de idoneidad toda injerencia en los derechos fundamentales debe ser apta o capaz para fomentar un objetivo constitucionalmente legítimo. En otros términos, supone la legitimidad constitucional del objetivo $y$, la suficiencia de la medida utilizada ${ }^{1}$. 
4. Proporcionalidad: De acuerdo con este principio para que una injerencia en los derechos fundamentales sea legítima, el grado de realización del objetivo de intervención debe ser por lo menos equivalente o proporcional al grado de afectación del derecho fundamental. Se trata, por tanto, de la comparación de dos intensidades o grados: la realización del fin de la medida examinada y la afectación del derecho fundamental ${ }^{2}$. La motivación que haga el Juez en la resolución debe consagrar un simple juicio de proporciones entre el sacrificio del derecho y el fin investigador que se pretende con su adopción. La doctrina alemana introduce el éxito previsible de la medida con un elemento a tener en cuenta para su dictado, descartando su aplicación cuando sea posible prever su escaso éxito.

\section{Marco normativo de las intervenciones a las comunicaciones}

Nuestro ordenamiento jurídico ha consagrado el derecho al secreto y a la inviolabilidad de las comunicaciones, elevándolo a rango constitucional al estar previsto en nuestra Constitución en el inciso 10 del Artículo 2 y en donde además se recogen los demás derechos fundamentales del que goza toda persona. El derecho al secreto de las comunicaciones cede por mandamiento motivado del juez, con las garantías previstas en la ley, así lo señala la misma Constitución. Los artículos 230 y 231 del NCPP, regula el procedimiento y ejecución de la medida de intervención de las comunicaciones, sin embargo esta regulación de carácter general ha de ser complementada con la producción jurisprudencial.

\section{Las intervenciones telefónicas}

Se entiende por intervención telefónica todo acto de investigación, limitativo del derecho fundamental al secreto de las comunicaciones, por el que el Juez de la Investigación Preparatoria, en relación con un hecho punible de especial gravedad y en el curso del procedimiento penal, decide, mediante auto especialmente motivado, que por la autoridad o funcionario, policial o de la propia fiscalía proceda al registro de llamadas y/o a efectuar las grabaciones magnetofónicas de las conversaciones telefónicas del investigado o de personas de las que cabe estimar fundadamente, en mérito a datos objetivos determinados que reciben o tramitan por cuenta del investigado determinadas comunicaciones, o que el investigado utiliza su comunicación, durante el tiempo imprescindible para preconstituir la prueba del hecho punible y la participación de su autor.

\section{Principio de proporcionalidad y presupuestos para la adopción de las intervenciones telefónicas}

Debido a que las intervenciones telefónicas restringen el derecho fundamental al secreto de las comunicaciones, su autorización por el Juez debe ceñirse

$2 \quad \mathrm{STC}^{\circ}{ }^{\circ}$ 00034-2004-PI/TC del 15 de Febrero del 2005. F.J. 63. 
de manera estricta a los cánones del principio de proporcionalidad, para este cometido se tendrá en cuenta los siguientes presupuestos:

1. Legalidad.- Como adelantamos, toda limitación a un derecho fundamental, debe estar revestido del principio procesal de "legalidad", que implica que la medida limitativa debe estar prevista por ley, dicha autorización legal para disponer esta medida la encontramos en la Constitución Política, la que adiciona además el carácter judicial de la medida por lo que sólo la autoridad judicial puede disponerla.

2. Necesidad.- Se dice que no basta que la medida este prevista en la ley y sea adoptada por un Juez, sino que es indispensable que objetivamente se justifique para cumplir con los fines constitucionales que la legitiman, siendo imperativo que en caso se presente otra alternativa menos gravosa, se adopte esta. Al respecto la Sentencia del Tribunal Supremo de España en el caso $N^{\circ}$ 14.6.193 en su fundamento jurídico, ha señalado : “...la resolución autorizando la escucha telefónica de las conversaciones telefónicas de una persona tiene que concederse con carácter excepcional y siempre que no exista otro medio de investigación menos incisivo que permita el desenvolvimiento de la actividad judicial sin interferirse y dañar derechos y libertades fundamentales de carácter trascendental para el libre desarrollo de la libertad y seguridad del individuo como el derecho al respeto a la intimidad personal y al secreto de las comunicaciones telefónicas".

El principio de necesidad en las intervenciones telefónicas siguiendo al maestro procesalista Vicente Gimeno Sendra, implica a su vez dos presupuestos procesales, uno de carácter material y otro de carácter procesal.

- Presupuesto material, desde este punto de vista jurídico sustantivo la adopción de la intervención telefónica exige que el objeto de la investigación los constituya un delito grave. El artículo 230.1 del NCPP limita para aquellos delitos sancionados con pena superior a los cuatro años de privación de la libertad, debiendo entender que está referido al extremo mínimo de la pena conminada pues lo contrario no se condice con el carácter excepcional y restringido de la medida. Nuestro nuevo código a diferencia de la ley que regula la intervención de las comunicaciones introduce un criterio cuantitativo relacionado al "quantum" de la pena a imponer por el delito imputado y deja de lado el listado de los delitos graves en el que habría que adoptar la medida restrictiva.

- Presupuesto Procesal, se requiere que la petición fiscal debe realizarse necesariamente dentro de la investigación preparatoria, descartándose su dictado en las diligencias preliminares, de ahí que el artículo 338.4 del NCPP, 
exija al Fiscal la formalización de la Investigación Preparatoria a efectos de solicitar medidas coercitivas.

\section{El procedimiento de intervención}

Dictaminada por el Juez la intervención telefónica, la autoridad o funcionario, policial o de la propia Fiscalía, se encargarán de la intervención y grabación de las escuchas para lo cual las empresas telefónicas y de telecomunicaciones, se encuentra obligadas a posibilitar la realización de la diligencia bajo apercibimiento de ser denunciados por delito de desobediencia a la autoridad; la diligencia que se llevará a cabo dentro del plazo fijado en la resolución que la concede. Una vez practicadas y documentadas mediante su grabación magnetofónica o por medio de otros medios técnicos análogos, estas grabaciones serán entregadas al Fiscal, quien dispondrá su conservación con todas las medidas de seguridad correspondientes y cuidará que la misma no sea conocida por terceras personas. El Fiscal dispondrá la transcripción escrita de la grabación, levantándose el acta correspondiente, sin perjuicio de conservar los originales de la grabación. Las comunicaciones que fueren irrelevantes para el procedimiento serán entregadas, en su oportunidad, a las personas afectadas con la medida, y se destruirá toda la transcripción o copias de ellas por el Ministerio Público.

Una vez ejecutada la medida de intervención y realizadas las investigaciones inmediatas en relación al resultado de aquélla, se pondrá en conocimiento del afectado todo lo actuado, quien puede instar el reexamen judicial, dentro del plazo de tres días de notificado. La notificación al afectado sólo será posible si el objeto de la investigación lo permitiere y en tanto no pusiere en peligro la vida o la integridad corporal de terceras personas. El secreto de las mismas requerirá resolución judicial motivada y estará sujeta a un plazo que el Juez fijará.

La audiencia judicial de reexamen de la intervención se realizará en el más breve plazo. Estará dirigida a verificar sus resultados y que el afectado haga valer sus derechos y, en su caso, impugnar las decisiones dictadas en ese acto.

\section{Plazo de duración}

Conforme lo dispuesto por el artículo 230.6, el plazo de duración de la intervenciones telefónicas, salvo solicitud de prórroga, no puede ser superior a los treinta días, excepcionalmente podrá prorrogarse por plazos sucesivos, previo requerimiento del Fiscal y decisión motivada del Juez de la Investigación Preparatoria. 


\section{Resolución Judicial que dispone la Intervención de la Comunicaciones con el Nuevo Código Procesal Penal}

Resolución $\mathrm{N}^{\circ} 01$

Moquegua dieciocho de abril del dos mil ocho.

VISTOS: El requerimiento de medida limitativa de derechos control de comunicaciones a realizarse en la intervención, grabación o registro de comunicaciones telefónicas y reporte de llamadas entrantes y salientes, desplazamiento de las celdas activas de los números Telefónicos por las empresas NEXTEL S.A.C, telefónica Móvil S.A.C, Telefónica del Perú y Américo Móvil (Claro) S.A.C. solicitada por el primer Despacho de Investigación de la Fiscalía Provincial corporativa de Mariscal Nieto Moquegua, en la investigación preparatoria seguida contra Silverio Chimayco Méndez, Roche Walter Pérez Yucra y Esteban Lunasco Taype por el Delito Tráfico Ilícito de Drogas; y, CONSIDERANDO: PRIMERO: Tal como lo estipula en el artículo 157 inc. 1 del Código Procesal Penal toda prueba debe ser legítima y lícita, esto es que no vulnere los derechos fundamentales y garantías de las personas, ni las facultades de los sujetos procesales; sin embargo, existen diligencias de averiguación directa, que importan limitaciones de estos derechos fundamentales en tanto se trata de actos de autoridad destinados a garantizar el proceso de conocimiento, actos en el que se interfiere en el derecho fundamental de una persona SEGUNDO: En el presente requerimiento, se verifica que se ha encontrado que el imputado Roche Walter Pérez Yucra ha mantenido comunicaciones vía teléfono celular con los imputados Silverio Chimayco Méndez, el menor Pilayo Gastelú Chiua que aparecen en el acta de la memoria celular registrados como "cojo", "desconocido" y ante la no colaboración de los imputados, se estaría verificando la comisión Modus Operando de una organización dedicada al Tráfico Ilícito de Drogas establecido en el Art. 296, con la agravante del Art. 297 numeral 6 del Código Penal por lo tanto se tiene que amparar intereses generales, es por ello que emerge el principio de proporcionabilidad establecido en sus sub principio de idoneidad, necesidad y proporcionalidad estricta por ello la intervención en los teléfonos es el medio idóneo para la obtención de pruebas, existe la necesidad, a efectos de recabar el caudal probatorio y efectivamente dada la trascendencia del ilícito por el interés general se puede verificar la proporcionabilidad estricta, la necesidad de saber la identidad de los titulares de los teléfonos, y la ubicación de donde se emite las mismas desde el primero de marzo del dos mil ocho hasta el dieciséis de abril del dos mil ocho lo que causan en este Despacho suficientes elementos de convicción para acceder al requerimiento. TERCERO: La finalidad del requerimiento es la función persecutoria del delito, pudiendo con ello suministrarse elementos que hagan factible la pretensión punitiva, buscando las conexiones de los imputados para la 
obtención de la droga por lo que estos presupuestos se encuentran determinados en los parámetros de proporcionabilidad y necesidad por los argumentos expuestos SE RESUELVE: Declarar Fundado el requerimiento del Ministerio Público, consecuentemente AUTORIZAR la diligencia de Medidas Limitativas de Derecho - Control de Comunicaciones, intervención grabación o registro de comunicaciones telefónicas y reporte de llamadas entrantes y salientes, además del desplazamiento de celdas activadas en los siguientes números telefónicos: 1.-669949151, 669914224, 669908344, 66965798, 66970955, 669639770, 669685966, 669989073, 669916399, 76377542, 669616702, 69741016, 669924081, 669735240, 669669074, 669977423, 669916389, 76742124, 69301912, 97238459, 669792769, 196165691, 9741118, 669978308, 9794361,198948154, 0569454650, 0669926695, 0669782838, 9760161, 0669792769, 669949151, 519465092, 72088926, 76746432, 0669737274, 0669792769, 66994915, 519465092; por el término no mayor a treinta días a cargo de las empresas NEXTEL S.A.C., Telefónica Móvil S.A.C, Telefónica del Perú y América Móvil (Claro) SA.C, quienes deberán guardar absoluta reserva e informar de las llamadas emitidas desde el primero de marzo dos mil ocho hasta el dieciséis de abril del dos mil ocho con indicación de duración e IMEI, localización a tiempo real de las líneas telefónicas e IMEI, mensajes de texto y e-mail entrantes y salientes, ubicación de IP, debiendo remitir la información a la Fiscalía Provincial Penal Corporativa de Mariscal Nieto Moquegua - Primer Despacho Fiscal de Investigación y al correo electrónico jopego5@,hotmail. com en el plazo de veinticuatro horas bajo apercibimiento de lo estipulado en el Art. 230 numeral 4. Para tal efecto deberán cursarse los oficios respectivos.

\section{Tómese razón y hágase saber.}

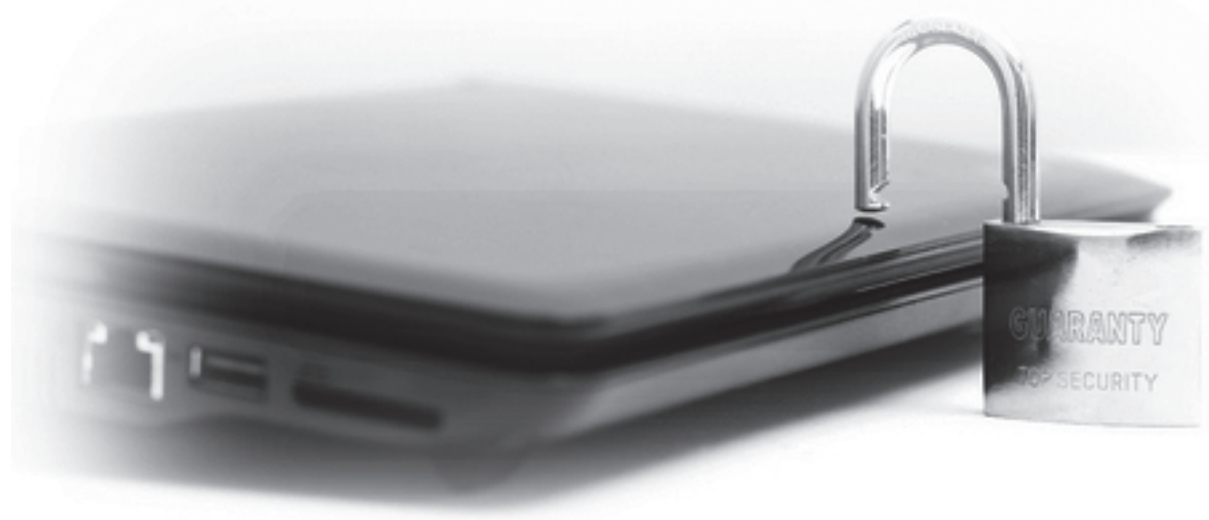

INTERVENCIÓN DE LA COMUNICACIÓN 
YANNYM. GORDILLO MANRIQUE

ÓRGANO : JUZGADO DE LA INVESTIGACIÓN

PREPARATORIA DE MOQUEGUA / ILO

EXPEDIENTE : 2008-00312-21-2801-JR-PE-1

ESPECIALISTA : RONALD CHACÓN HURTADO

IMPUTADO : LUNASCOTAYPE ESTEBAN - PÉREZ YUCRA ROCHE WALTER

DELITO : $\quad$ ART. 296.- PROMOCIÓN O FAVORECIMIENTO AL TRÁFICO ILÍCITO DE DROGAS

ART. 297.- FORMAS AGRAVADAS DE TRÁFICO ILÍCITO DE DROGAS 